\title{
Data Processing of Fault Recorder in Power System
}

\author{
Yu Qin, Yu Bai, Minghao Wen \\ School of Electrical and Electronic Engineering, Huazhong University of Science and Technology, Wuhan, China \\ Email:501916850@qq.com
}

How to cite this paper: Qin, Y., Bai, Y. and Wen, M.H. (2017) Data Processing of Fault Recorder in Power System. Energy and Power Engineering, 9, 46-52. https://doi.org/10.4236/epe.2017.94B006

Received: March 2, 2017

Accepted: March 30, 2017

Published: April 6, 2017

\begin{abstract}
This article studies the fault recorder in power system and introduces the Comtrade format. Andituses $\mathrm{C}++$ programming to read recorded fault data and adopts Fourier analysis and symmetrical component method to filter and extract fundamental waves. Finally the effectiveness of the data processing method introduced in this paper is verified by CAAP software.
\end{abstract}

\section{Keywords}

Fault Recorder, Read and Process Recorded Fault Data, Result Verification

\section{Introduction}

No matter the power system works properly or breaks down, the fault recorder can always record amounts of detailed data, which is not only the basis to analyze the fault cause and test the relay protection action, but also provides valuable information for the power workers to study the real behaviors of the complex system and find the law. That makes us understand the momentary changes of electrical quantities timely.

After obtaining the failure data, we have to think about how to separate those electrical components and symmetrical components from the tens of thousands of sampling points. The Fourier transform can filter the collected signals and extract the fundamental frequency component. When unbalanced fault occurs, the symmetrical component transformation can extract the positive, negative and zero sequence components, complete the calculation in their respective single-phase network and combine the results to get electric quantities of threephase unbalanced circuit. This is the initial processing of recorded fault data.

\section{The Fault Recorder in Power System}

The fault recorder is a kind of automatic device which can record the running 
parameters such as voltage, current, power and the action of protection devices at the first time when the power system breaks down. The development of fault recorder has experienced three main stages: ink type fault recorder, photoelectric fault recorder and digital fault recorder [1]. The first two generations are mechanical, while the third one is of microcomputer type, which has relatively longer recording time, more complete and perfect intelligent printing capabilities of graphics, etc..

The fault recorders vary in different countries and different voltage classes. In the literature [2], the devices can be classified based on the principle of recording, the performance of the device and the form of the circuit. According to the recording principle, the fault recording devices can be divided into the light type, the printing type, the magnetic circuit type and the digital type. Among the above four types, the light type has mature technologies, simple devices, easy operation and high accuracy, which is widely used in China. While the printing type has been discontinued in our country because of its old structure and low recording accuracy, the magnetic circuit type can reach higher accuracy. However, the requirements on the manufacturing process of it are high and it has complex reading and writing devices, so this type is not produced now. The digital type, which has high precision, is advanced, but the wiring is complex and has high cost. It's generally used in high voltage or extra high voltage transmission lines. With the rapid development of electric power industry, the digital wave recording devices are becoming popular.

The $220 \mathrm{kV}$ - $500 \mathrm{kV}$ Power system fault dynamic record technical guidelines states that during the entire process of the fault, the data recorded shall be carried out in accordance with the time sequence, as shown in Figure 1 [3].

Table 1 shows the data acquisition and recording time at different periods:

\section{Comtrade}

The Fault Recorder is the device to record fault data, while COMTRADE is a common format for different devices in the power system to exchange recorded fault data and transient waveforms. The full name of it is IEEE Standard Common Format for Transient Data Exchange for Power Systems. COMTRADE standard currently has two versions-the 1991 and the 1999. The latter version can be compatible with the former one. The specific differences between the mare that the 1999 version includes information files which the 1991 version doesn't have. And also, the configuration files of the 1999 version are more comprehensive [4] [5].

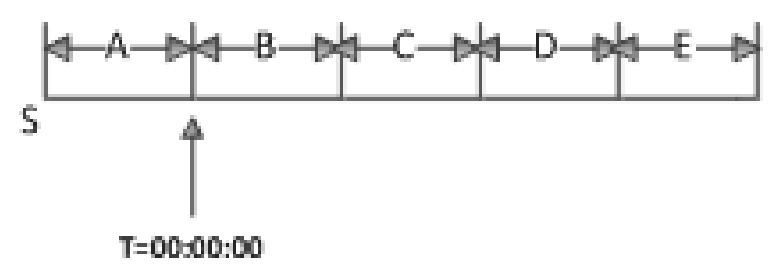

Figure 1. Time sequence. 
Table 1. Information of data acquisition.

\begin{tabular}{|c|c|c|}
\hline Period & Data Acquisition & $\begin{array}{l}\text { Recording } \\
\text { Time }\end{array}$ \\
\hline A & $\begin{array}{l}\text { Collect the state data before the disturbance, output } \\
\text { the original acquisition waveform }\end{array}$ & $\geq 0.04 \mathrm{~s}$ \\
\hline B & $\begin{array}{l}\text { Collect the state data in the early stage of the disturbance, } \\
\text { output the original acquisition waveform }\end{array}$ & $\geq 0.1 \mathrm{~s}$ \\
\hline $\mathrm{C}$ & $\begin{array}{l}\text { Collect the state data in the middle stage of the disturbance, } \\
\text { output continuous power frequency effective values }\end{array}$ & $\geq 1.0 \mathrm{~s}$ \\
\hline $\mathrm{D}$ & $\begin{array}{l}\text { Collect system dynamic process data, output a } \\
\text { power frequency effective value per } 0.1 \mathrm{~s}\end{array}$ & $\geq 20 \mathrm{~s}$ \\
\hline $\mathrm{E}$ & $\begin{array}{l}\text { Collect dynamic data of the long process of the system, } \\
\text { output a power frequency effective value per } 0.1 \mathrm{~s}\end{array}$ & $\geq 10 \mathrm{~min}$ \\
\hline
\end{tabular}

According to the literature [6] [7] [8], each record in COMDTRADE standard includes four documents-header file, configuration file, data file and information file [9].

Header file, named ".HDR", is an optional ASCII text file. It can help users understand the conditions of the data record. Parameters like states of the grid before disturbance occurs, corresponding station names of fault data, identifications of fault lines, reactors, transformers or circuit breakers, the length of the fault line, the positive sequence and zero sequence resistance and reactance of the line, the mutual inductance between lines, positions and ratings of shunt reactors and series capacitors, the rated voltage of TV and TA, the rated power and wiring group of transformers, the parameters of each node in the grid and so on are all included in this file.

Configuration file, named ".CFG", is used to define the recording style of the data file. It is divided into several lines, with each line ended by enter or newline and data is separated by commas. Station names, device characteristics, version numbers of Comtrade, information of the channels (A/D), the grid frequency, sampling information, the date/time scale and the type of data file are included in this file.

Data file, named. "DAT", contains all input channel values of each sampling. It also contains a sequence number and the time mark of each sampling at the beginning of a line. Each point is recorded in the order described in the configuration file. Data file can be divided into ASCII file and binary file, whose reading methods are different. In ASCII file, the code and the output character is corresponding and a byte represents a character, which is easy to read. While the binary file outputs data based on its storage form is in the computer memory. It is a continuous stream of binary data with no delimiters. In ASCII file, the recorded value of each sample point is arranged as: $n$, timestamp, A1, A2, ... Ak, $\mathrm{D} 1, \mathrm{D} 2, \cdots, \mathrm{Dm}<\mathrm{CR} / \mathrm{LF}>$; In the binary file, it's arranged as: $\mathrm{n}$ timestamp A1 A2, .., Ak S1 S2, .., Sm.

Information file, named ".INF", is optional, stored separately, and also in the 
form of ASCII. It can maintain the compatibility between the programs in Comtrade format. It consists of a number of areas and each area contains the header and a number of entries to explain and record additional information.

\section{The Reading Process of the Recorded Fault Data}

\subsection{Read the Configuration File}

It should define a structure named CFG data to storage data, using a custom function Read CFG to read line by line and save variables. The reading process will use the VC++ file flow, as shown Figure 2.

\subsection{Read the Data File}

Reading data files also rely on VC++ program file stream. It defines the DAT structure which is used to store the three-phase voltage and current data. Read ASC function and Read Binary function are used to read files and save variables, to which should be passed the corresponding data file and DAT structure before called.

\subsection{Read Header File}

Since the header file is in ASCII form, it can be read in the way similar to that of the configuration file. It should define a Readhead function to read the line length, positive/zero sequence resistance and reactance, current/voltage ratio of transformers, and also save the variables.

\section{Data Processing}

\subsection{Extract the Fundamental Component by Fourier Transform}

The microcomputer protection devices will react when the fault occurs. The signal contains the decaying DC component and the complex harmonic components, which will cause serious distortion to the waveform. Therefore, the collected signals should be filtered and the frequency component should be extracted, which can be realized by Fourier transform.

Full wave Fourier algorithm [10] [11] requires a cycle data window and the amount of its computations is medium. It extracts the specific frequency component based on the orthogonality property. The specific calculation formulas

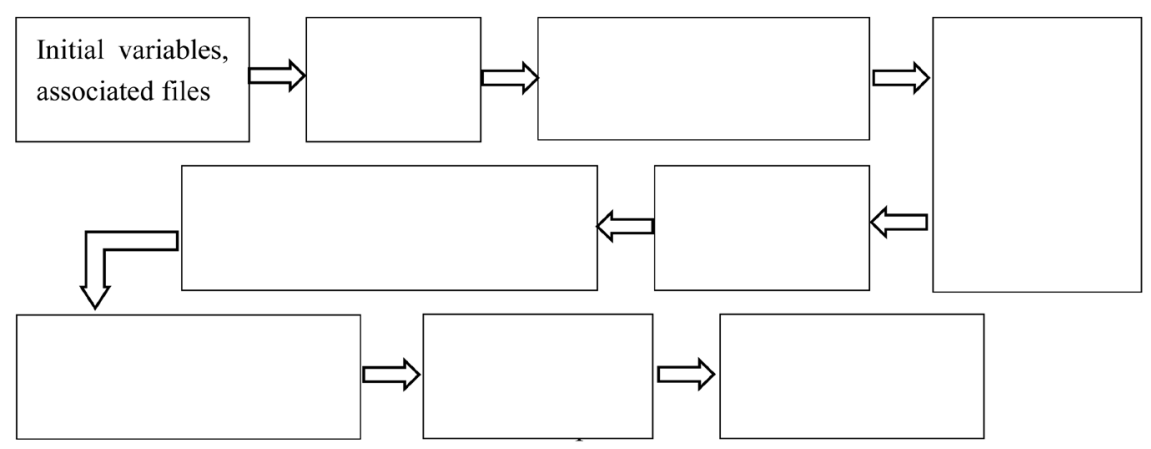

Figure 2. VC++ file flow. 
are:

$$
\begin{gathered}
x(t)=\frac{a_{0}}{2}+\sum_{n=1}^{\infty}\left[a_{n} \cos n w_{1} t+b_{n} \sin w_{1} t\right] \\
\left\{\begin{array} { l } 
{ a _ { 1 } = \frac { 2 } { T } \int _ { 0 } ^ { T } x ( t ) \operatorname { c o s } w _ { 1 } t d t } \\
{ b _ { 1 } = \frac { 2 } { T } \int _ { 0 } ^ { T } x ( t ) \operatorname { s i n } w _ { 1 } t d t }
\end{array} \left\{\begin{array}{l}
X=\sqrt{\frac{a_{1}^{2}+b_{1}^{2}}{2}} \\
t g a_{1}=\frac{a_{1}}{b_{1}}
\end{array}\right.\right.
\end{gathered}
$$

\subsection{Extract Sequence Component by the Symmetrical Component Method}

The electromagnetic coupling relationships between the three-phase transmission lines bring much difficult to the calculation. So the symmetrical component transformation should be adopted to decouple three-phase into three independent modules and extract the positive, negative and zero sequence component separately. Complete the calculation in their respective single-phase network and combine the results to get electric quantities of three-phase unbalanced circuit.

Take a phase current as an example, the sequence component is obtained by the following methods [12]:

$$
\left[\begin{array}{l}
I_{a(1)} \\
I_{a(2)} \\
I_{a(0)}
\end{array}\right]=\frac{1}{3}\left[\begin{array}{ccc}
1 & a & a^{2} \\
1 & a^{2} & a \\
1 & 1 & 1
\end{array}\right]\left[\begin{array}{c}
I_{A} \\
I_{B} \\
I_{C}
\end{array}\right],\left[\begin{array}{c}
I_{A} \\
I_{B} \\
I_{C}
\end{array}\right]=\left[\begin{array}{ccc}
1 & 1 & 1 \\
a^{2} & a & 1 \\
a & a^{2} & 1
\end{array}\right]\left[\begin{array}{c}
I_{a(1)} \\
I_{a(2)} \\
I_{a(0)}
\end{array}\right]
$$

\section{Verify the Results with CAAP}

CAAP, made in Wuhan Zhongyuan Science and Technology Company with standard $\mathrm{C}++$ language, is a software to analyze recorded fault data in power system. It can accomplish the following works:

\subsection{Read Data}

It can display and compare waveforms. Also, values of both sides, instantaneous value, real effective value, the phase, the location of the point in the data file and the corresponding time can be viewed. Take B Station of Sha-GuangJia Line as an example, the waveform displayed in CAAP and the waveform read by programming are shown in Figure 3.

\subsection{Harmonic Analysis}

CAAP software can show waveforms and spectrums of the DC component, the fundamental component and harmonic components, which can check the waveforms obtained by Fourier Transform. Take South Station of Sha-GuangJia Line as an example, the waveform displayed in CAAP software and the waveform obtained by programming are shown in Figure 4.

\subsection{Sequence Component Analysis}

CAAP can analyze sequence components of three-phase voltage/current indivi- 
dually or together and also zoom and hide these components. Take South Station of Sha-GuangJia Line as an example, the sequence components of the fault point displayed in CAAP and programmed by MATLAB are shown in Figure 5.

The comparisons above indicate that the results obtained by programming are identical to those displayed in CAAP, which means methods discussed in this paper to read files and process data are correct and effective.

\section{Summary}

This paper studies the fault recorder in power system and the method to process recorded fault data. It uses $\mathrm{C}++$ programming to read data and Fourier analysis and symmetrical component method to filter and extract fundamental waves. The results obtained by this method accord with the results displayed in CAAP software.

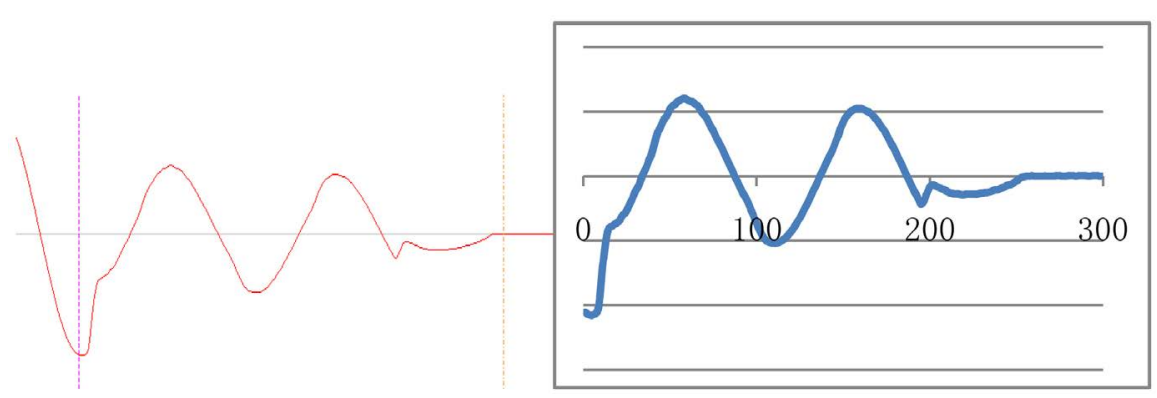

Figure 3. Waveform comparison.

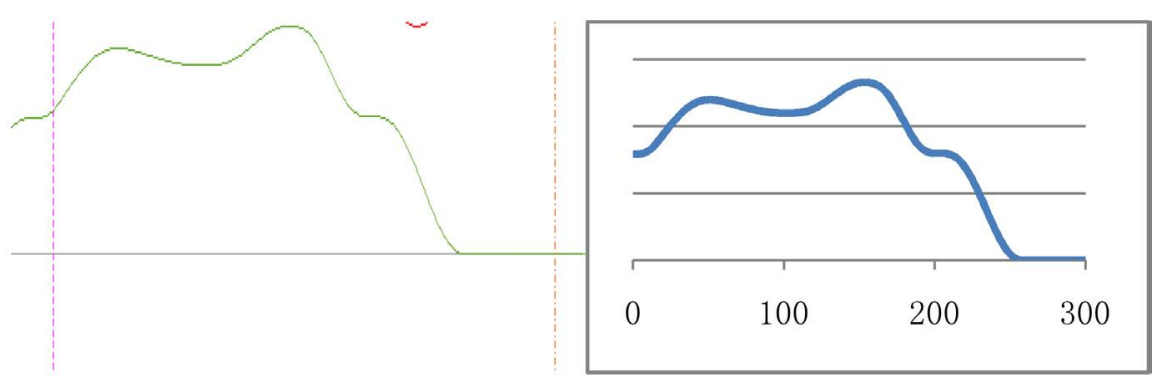

Figure 4. Waveform comparison.
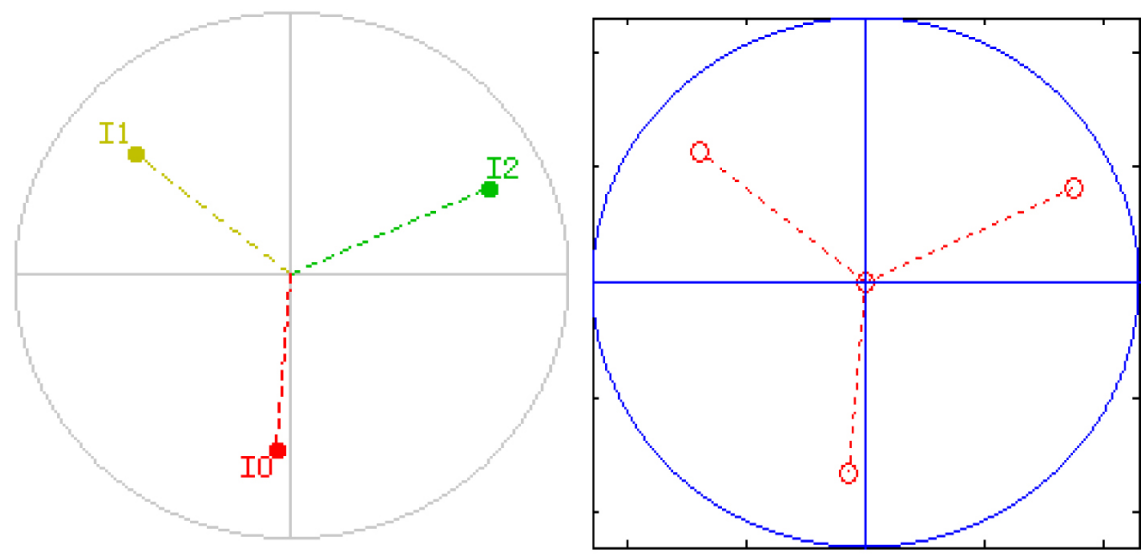

Figure 5. Waveform comparison. 


\section{Acknowledgements}

This work was supported by the National Natural Science Foundation of China (51477061).

\section{References}

[1] Lin, Y.L. (2005) TheAnalysis and Research of Recorded Fault Data. North China Electric Power University.

[2] (1987) Northeast and Southwest Electric Power Design Institute of Ministry of Electric Power Industry, Principle and Application of Fault Recorder, Electric Power Industry Press.

[3] 553-94 DL/T. People's Republic of China 220kV 500kV Power System Fault Dynamic Recording Technical Guidelines.

[4] Cai,C.L., Ge, X., Xu, J.J.andNi, Y.(2009) Analysis, Display and Analysis of Data Files In ComTradeFormat.Metallurgical Automation.

[5] Guo, Z.H.(2011) Analysis Method and Software Design of Power Fault Recording Data. Hunan University.

[6] GB/T 22386-2008/IEC 60255-24.2001. General format of People's Republic of China Power System Transient Data Exchange.

[7] (2005) Power Systems Relay Committeeof theIEEE Power Engineering Society, IEEE Standard Common Format for Transient Data Exchange (COMTRADE) for Power Systems, IEEE Std C37.111 ${ }^{\mathrm{Tm}}$ - (R2005), New York,USA.

[8] Phadke,A.G., Chainnrm,J.A. and Jodice. COMTRADE:ANew Standard for Common Format for Transient Data Exchange.IEEE Transactions on Power Delivery,7.

[9] He, J.L., Li, Y.L., Dong, X.Z. and Li, B. (2010) Principle of Relay Protection. China Electric Power Press.

[10] Mou, L.H. andJin, M. (2007) Analysis of Microcomputer Based Protection Fourier Algorithm. Automation of Electric Power System.

[11] He, Y.Z. and Wen, Z.Y. (2002) Power system analysis Third Edition, Huazhong University of Science and Technology Press.

[12] Bermu'dez,O.E.(2006) Computational Tool for Advanced Analysis of Fault Recordings. Transmission \& Distribution Conference and Exposition:Latin America.

\section{Scientific Research Publishing}

Submit or recommend next manuscript to SCIRP and we will provide best service for you:

Accepting pre-submission inquiries through Email, Facebook, LinkedIn, Twitter, etc. A wide selection of journals (inclusive of 9 subjects, more than 200 journals)

Providing 24-hour high-quality service

User-friendly online submission system

Fair and swift peer-review system

Efficient typesetting and proofreading procedure

Display of the result of downloads and visits, as well as the number of cited articles

Maximum dissemination of your research work

Submit your manuscript at: http://papersubmission.scirp.org/

Or contact epe@scirp.org 